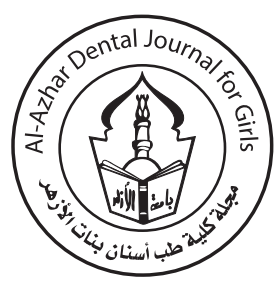

\title{
Evaluation of Fracture Resistance of Some Contemporary Class II Glass Ionomer Restorations at Different Time Intervals
}

\author{
Nafesa Mostafa Ali Sakr ${ }^{(1)}$, Maha Ahmed Niazy ${ }^{(2)}$ and Nevin Abd-El-Aziz Gad ${ }^{(3)}$
}

Codex : 06/1901

azhardentj@azhar.edu.eg

http://adjg.journals.ekb.eg

DOI: 10.21608/adjg.2019.5980.1037

\section{KEYWORDS}

Amalgomer $C R$,

Equia Fort fil,

Equia fil,

fracture resistance,

thermocycling

\begin{abstract}
Purpose: was to evaluate and compare fracture resistance of some contemporary glass ionomer restorations (Amalgomer CR, EQUIA Fort fil and EQUIA fil) in class II cavities at different time intervals. Materials and Methods: A total of 90 class II cavities were prepared in extracted maxillary premolars $(n=90)$. The samples were divided into three main groups (30 each) according to the materials; These three groups were further subdivided into three groups according to assessment time; 24 hours, one month and three months. Each material was applied to the cavity according to manufactures' instructions. Samples were stored in artificial saliva for the study storage periods. At the end of each storage period samples were subjected to thermocycling at $5^{\circ} \mathrm{C}$ and $55^{\circ} \mathrm{C}$ for 1000 cycles. The samples were subjected to fracture resistance test using universal testing machine. Failure modes were evaluated using stereomicroscope and micromorphology of fractured restorations and tooth restoration interface were evaluated using Scanning Electron Microscope (ESM). Results: the results revealed that the highest mean value recorded for Amalgomer CR followed by Equia Fort fil while Equia fil recorded the lowest mean value. Also the results revealed that the highest mean value recorded after three months storage followed by one moth storage while one month storage recorded the lowest mean value. Conclusions: Fracture resistance of cone temporary glass ionomers in class II cavities is affected by storage for 3 months. Ceramic reinforced glass ionomer (Amalgomer CR) appears promising regarding fracture resistance.
\end{abstract}

\section{INTRODUCTION}

Glass ionomers were invented in 1969 and reported by Wilson and Kent in the early 1970s in response to the need for a bland, adhesive filling material. It is the product of acid base reaction between an

- $\quad$ Paper extracted from Master thesis titled "Evaluation of Fracture Resistance of Some Contemporary Class II Glass Ionomer Restorations at Different Time Intervals".

1. Demonstrator of operative dentistry Department, Faculty of Dental Medicine for Girls, Al-Azhar University, Egypt.

2. Professor of Operative Dentistry, Faculty of Dental Medicine for Girls, Al-Azhar University, Egypt.

3. Lecturer of Operative dentistry, Faculty of Dental Medicine for Girls, Al-Azhar University, Egypt. 
ion-leachable glass and an aqueous solution of polyalkenoic acid. During the reaction, polyanion in the liquid polymerized to a matrix cross linked with metal ions to form a hard gel ${ }^{(1,2)}$. Glass polyalkenoates are materials made of glass powder of aluminofluorosilicate combined with a water soluble polymer. Such materials were called by Kent as "glass ionomer" cements, and that name has become popular in the dental field ${ }^{(3)}$.

The original glass ionomer formulations developed in the 1970s failed to gain much interest from dental clinicians. Those materials were water sensitive, required extended setting time, and had weak strength properties after hardening including (wear resistance and fracture toughness). Although glass ionomers have advantages of chemical adhesion to tooth structure, fluoride ions release, biocompatibility and good coefficients of thermal expansion with tooth structure, but the dentists did not support its use as it has difficult handling, prolonged working time, and proved not reliable in the long term use because of poor durability ${ }^{(4,5)}$.

Today, highly viscous glass ionomer cements (GICs) (Equia, GC, Tokyo, Japan) when compared to traditional GICs appeared to have superior physical properties due to good particle size distribution and polyacid optimization, resulting in a high crosslinkage in the GIC matrix ${ }^{(6)}$

Equia Forte which combines a protective composite coating with a filling component represents the next step in the development of the proven Equia concept. It is called glass hybrids (GHs) and based on newly introduced hybrid technology. Reinforcement of glass hybrids has evolved by higher molecular weight acrylic acid molecules and a second, smaller, and more reactive silicate particles, which supposed to increase matrix crosslinking. This, in turn, is suggested to improve the material's flexural strength. Furthermore, esthetic appearance and wear resistance are supposed to be improved by covering these restorations with a resin layer ${ }^{(7)}$.
New generation of Ceramic reinforced GIC was introduced for added durability which called Amalgomer CR. Amalgomer CR is the first GIC to launch with ceramic. Special process of treatment and improvisation of the main glass Ionomer components, fluoroaluminosilcophosphate glass and polyalkenoic acids is used for manufacturing ${ }^{(8)}$. Ceramic reinforced glass ionomer restorative material was found to has physico-mechanical properties that are very similar and even higher than dental amalgam ${ }^{(9)}$.

It was found that the restoration resistance to damage in oral environment affects their clinical performance. The oral environment is likely suggested to cause more pronounced filler degradation than that caused by storage in distilled water ${ }^{(10)}$.

Therefore, the study was conducted to evaluate fracture resistance of some contemporary glass ionomer restoration (Amalgomer CR, Equia Forte fil, Equia fil) in class II cavities. Moreover micromorphological changes at the fractured restoration surface and tooth restoration interface were examined using Environmental Scanning Electron Microscope (ESEM). Also failure modes were evaluated using stereomicroscope.

\section{MATERIALS AND METHOD}

A total of 90 extracted human maxillary premolars were collected and examined for the presence of cracks or any other defects using stereomicroscope. Flattening was done for both occlusal and mesial surfaces using diamond disk mounted in cutting machine Demco (Dentallmaintenanc CO, Bonsall, calf. U.S.A, model E96) by cutting $1.5 \mathrm{~mm}$ beneath the cusp tips and $1 \mathrm{~mm}$ from the mesial surfaces. Teeth were then embedded up to $2 \mathrm{~mm}$ apical to the (CEJ) using teflon ring $(1.6 \mathrm{~cm}$ width $\mathrm{X} 2$ $\mathrm{cm}$ height) containing chemically cured activated acrylic resin. A long axis and occlusal plane were adjusted using dental surveyor.

Cavity preparation; Class II compound cavities (occluso-mesial cavities) were prepared in all teeth 
with the desired cavity depth and width. The occlusal box was $1.5 \mathrm{~mm}$ pulpal depth and $2.0 \mathrm{~mm}$ width. The proximal box was $3.0 \mathrm{~mm}$ in height, $2.0 \mathrm{~mm}$ in width and had a $1.5 \mathrm{~mm}$ axial depth ${ }^{(14)} 90$ degree cavo-surface margins were adjusted. Roundation was done for line angles; the facial and palatal cavity walls were cut with parallelism between them on both the occlusal and proximal portions of the cavity. Similarly, both axial walls of the masial and distal boxes were in parallelism with the tooth long axis Straight fissure carbide bur (Number 012, Komet Geber, Brasseler, Legmo, Germany) with a high speed hand piece (NSK, Pana Air, Nakanishi Inc Japan). Cavities dimension was standardized using mini size digital caliber. The samples were classified into three groups (30 each) according to the restorative materials; Amalgomer CR (A1), Equia Fort fil (A2) and Equia fil (A3). Each group were further subdivided into three subgroups according to storage time in artificial saliva; 24 hours (T1), 1 month (T2) and 3 months (T3). Composition and manufacturing of the study materials are presented in table (1).

Restorative procedures; A metallic matrix band was shaped and placed. The band was held firmly by matrix retainer against the proximal aspect being restored. Each material was used as recommended by its manufacturer.

In group (A1); Amalgomer CR specimen were placed. The powder: liquid ratio (1 scoop: 1 drop of water) was proportioned immediately prior to mixing. Mixing was done on glass slab using stainless steel spatula. Mix was carried to the cavity using non- stick aluminium instruments. The total working time was $90 \mathrm{sec}$. the beginning of mixing.

In group (A2 AND A3); Equia Forte fil and Equia fil were placed. Both materials are provided as capsule. Before activation the capsule was shaked to loosen the powder, then plunger was pushed until it was flushed with the main body to activate the capsule. Immediately after activation, the mixing was done for $10 \mathrm{sec}$. using amalgamator. The tritu- rated capsule was removed from amalgamator and loaded into a metallic capsule applier. The mixture was injected into the cavity through capsule nozzle. The total working time was $75 \mathrm{sec}$. from the beginning of mixing.

Finishing, polishing and coating the restoration: Restorations were Finished and polished under water spray using diamond burs and abrasive disks. After finishing, the dust was sprayed away then the specific coat for each material was applied to the restorations using micro brushes. Curing was done 10 seconds for each restoration surface using light emitting diode (LED) light curing unit (high power LED, optical fiber, light hood, lithium battery, power adapter and pedestal).

Storage of the specimens: Each main group $(n=30)$ was placed in a separate container of artificial saliva ( $\mathrm{PH} 7 \pm 1$ ) and stored at $37^{\circ} \mathrm{C} \pm 1$. Incubator (37 8C; BR 6000; Heraesus Kulzer) was used to fix temperature during storage periods. The artificial saliva was replenished every 24 hours ${ }^{(64)}$. Subgroups $(n=10)$ were removed from each main group at the end of each storage period ( 24 hours, 1 month and 3 months) and then subjected to thermocycling at $5^{\circ} \mathrm{C}$ and $55^{\circ} \mathrm{C}$ for 1,000 cycles. $30 \mathrm{sec}$. was the maintenance time at each temperature, and 10 seconds was the transferring time between the two temperatures using thermocycler (THE-1100 SD Mechatroniks thermocycler Germany).

\section{Fracture resistance assessment:}

Assessment of fracture resistance was done for all the samples. Universal testing machine (Model 3345; Instron (Instron® Bluehill Lite Software) was used for determining the samples Fracture resistance. Fracture test was done $1.5 \mathrm{~mm}$ from proximal marginal edge with $1.5 \mathrm{~mm}$ round tip of metallic rod at $1 \mathrm{~mm} / \mathrm{min}$ cross-head speed (fig.1). An audible fracture and sharp drop at load-deflection curve recorded using computer software (Bluehill Lite Software Instron ${ }^{\circledR}$ Instruments) were used for manifestation of failure load. Newton was the unite used for recording the load required to fracture. 


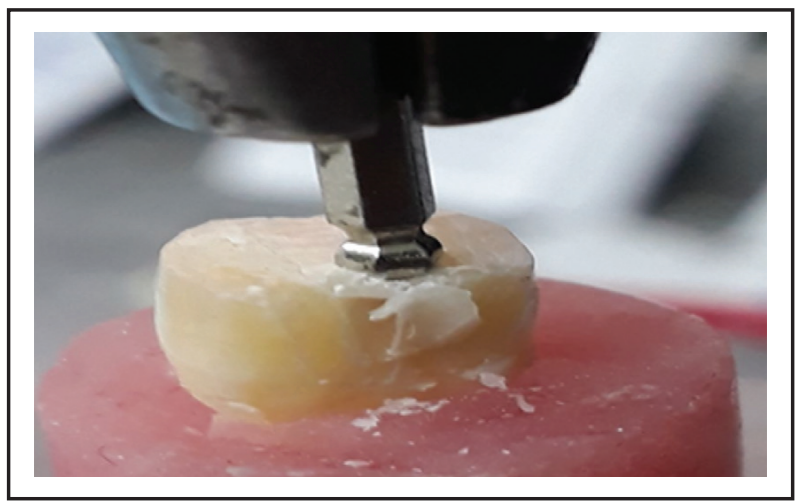

Fig. (1) Round tip for load application till fracture

\section{Assessment of mode of failure:}

Test of fracture was performed then examination of the specimens was performed using optical stereomicroscope with (40x) magnification to evaluate the mode of failure. Three types of failure modes were detected: 1 . If failure was $100 \%$ of the bonded interface between the tooth and restoration it was referred as adhesive failure. If failure was $100 \%$ in the material it was referred as cohesive failure while if failure was partially in bond and partially in material it was referred as mixed failure.

\section{Scanning Electron Microscope:}

Selected samples surfaces were examined using Scanning Electron Microscope (SEM) at 400X magnification for evaluating the morphological characterization of the fractured surface of the material. Also SEM analysis at $200 \mathrm{X}$ magnification was performed to evaluate gap width and morphological characteristic of tooth restoration interface of the fractured samples.

\section{Statistical Analysis}

Data were offered as mean, median, standard deviation, minimum, maximum with $95 \%$ Confidence Interval $(95 \% \mathrm{CI})$ for the mean values. The effects of types of materials, periods of storage and the interaction between them on fracture resistance were studied using ANOVA test. When significant was found with ANOVA pair-wise comparisons were done using Bonferroni's post-hoc test. The significance level was set at $\mathrm{P} \leq 0.05$. Statistical analysis was performed with IBM (IBM Corporation, NY, USA) was used for statistical analysis.

Table (1) Composition and manufacturing of the study materials.

\begin{tabular}{|c|c|c|c|}
\hline Materials and Brand & Composition & Manufacturer & Lot No. \\
\hline $\begin{array}{l}\text { Ceramic reinforced glass } \\
\text { ionomer } \\
\text { (Amalgomer CR) \& AH fil } \\
\text { LC Coat. }\end{array}$ & $\begin{array}{l}\text { Amalgomer CR: Powder: Fluoroaluminosilicate glass, polyacrylic } \\
\text { acid powder, tartaric acid powder and ceramic reinforcing powder. } \\
\text { Liquid: distilled water. } \\
\text { AH fil LC coat: viscous resinous liquid contains hydroxy ethyl meth- } \\
\text { acrylate. }\end{array}$ & $\begin{array}{l}\text { Advanced Health Care, } \\
\text { UK } \\
(\underline{\text { sales@ } @ \text { ahl.uk.com })}\end{array}$ & $111505-4$ \\
\hline $\begin{array}{l}\text { Hybrid glass system } \\
\text { (EQUIA Forte Fil \& } \\
\text { EQUIA Forte Coat). }\end{array}$ & $\begin{array}{l}\text { EQUIA Forte Fil: Powder: Fluoroaluminosilicate glass, polyacrylic } \\
\text { acid powder, surface-treated glass. } \\
\text { Liquid: aqueous polyacrylic acid. (Filler Content } \% \text { by weight/ \% by } \\
\text { volume) Not available. } \\
\text { EQUIA Forte Coat: Nano filled resin matrix combines both conven- } \\
\text { tional \&multifunctional MMA photoinitiators. }\end{array}$ & GC, Tokyo, Japan & $\begin{array}{l}1608081 \\
1507101\end{array}$ \\
\hline $\begin{array}{l}\text { High-viscosity glass iono- } \\
\text { mer cement (GIC) re- } \\
\text { storative material system } \\
\text { (EQUIA FIL \& EQUIA } \\
\text { Coat). }\end{array}$ & $\begin{array}{l}\text { EQUIAaFil: Powder: } 95 \% \text { strontium fluoroalumino-silicate glass, } 5 \% \\
\text { polyacrylic acid. } \\
\text { Liquid: } 40 \% \text { aqueous polyacrylic acid. } \\
\text { EQUIA Coat: } 50 \% \text { Methyl methacrylate, } 0.09 \% \text { camphorquinone. }\end{array}$ & GC, Tokyo, Japan & 1704191 \\
\hline
\end{tabular}




\section{RESULTS}

\section{Fracture resistance:}

Effect of material type regardless the storage time:

Comparing the mean value at different times, the result revealed that Amalgomer CR showed the statistically significant highest mean fracture resis-

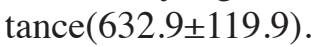

There was insignificant difference between Equia Forte fil (521.7 \pm 47.1$)$ and Equia fil $(488.5 \pm 74.6)$; both showed the statistically significant lowest mean fracture resistance values table (2) ( fig.2).

Effect of storage time regardless material type: Comparing the mean values at different times, the result revealed that there was insignificant difference between the mean fracture resistance after storage for 24 hours $(507 \pm 70.1)$ and one month (540 \pm 80.3$)$. The mean fracture resistance after storage for 3 months $(596 \pm 135.4)$ showed the statistically significant highest mean value compared with 24 hours and one month values table(3) ( fig.2).

\section{Failure modes:}

After evaluating mode of failure, it was found that the predominant failure type was cohesive fractures in the three materials at different storage times followed by mixed then adhesive type fractures. It was found that adhesive increased with time.

Table (2): The mean, standard deviation (SD) values and results of two-way ANOVA test for comparison between fracture resistance of the three materials regardless of storage time.

\begin{tabular}{|c|c|c|c|c|c|c|}
\hline \multicolumn{2}{|c|}{ Amalgomer CR } & \multicolumn{2}{c|}{ Equia Forte fil } & \multicolumn{2}{c|}{ Equia fil } & \multirow{2}{*}{-value } \\
\cline { 1 - 5 } Mean & SD & Mean & SD & Mean & SD & \\
\hline $632.9^{\mathrm{A}}$ & 119.9 & $521.7^{\mathrm{B}}$ & 47.1 & $488.5^{\mathrm{B}}$ & 74.6 & $<0.001 *$ \\
\hline
\end{tabular}

*: Significant at $P \leq 0.05$, Different superscripts in the same row are statistically significant.

Table (3): The mean, standard deviation (SD) values and results of two-way ANOVA test for comparison between fracture resistance at different storage times regardless of material.

\begin{tabular}{|c|c|c|c|c|c|c|}
\hline \multicolumn{2}{|c|}{ 24 hours } & \multicolumn{2}{c|}{ 1 month } & \multicolumn{2}{c|}{ 3 months } & \multirow{2}{*}{$\boldsymbol{P}$-value } \\
\cline { 1 - 3 } Mean & SD & Mean & SD & Mean & SD & $<0.001^{*}$ \\
\hline $507^{\text {в }}$ & 70.1 & $540^{\text {в }}$ & 80.3 & $596.5^{\mathrm{A}}$ & 135.4 & $<$ \\
\hline
\end{tabular}

*: Significant at $P \leq 0.05$, Different superscripts in the same row are statistically significant

\section{Scanning Electron Microscope:-}

Scaning pictures showed fractured restoration surface with reduced numbers and size of micro cracks and porosities with increased storage periods. Also gap width at tooth restorations interface appeared to be increased with time. (Fig. 3) representative scaning pictures for tooth restoration intreface with Amalgomer CR as an example at different sorage periods.

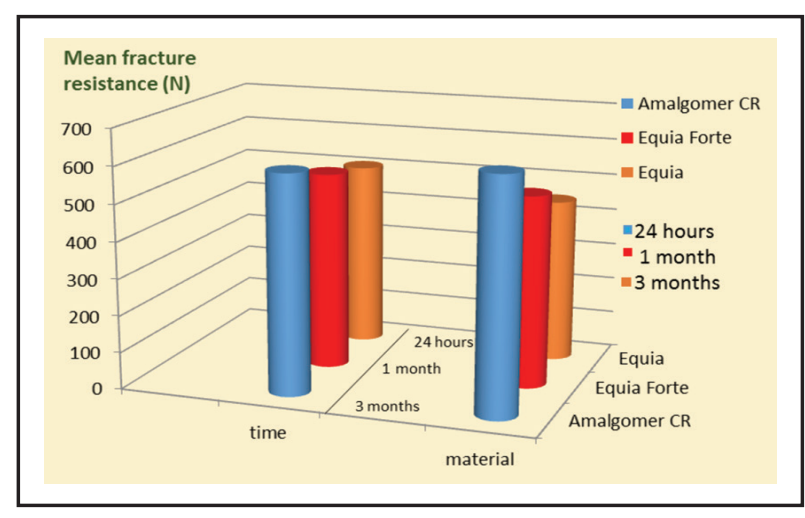

Fig. (2) Bar chart showing effect of time and material type on fracture resistances 


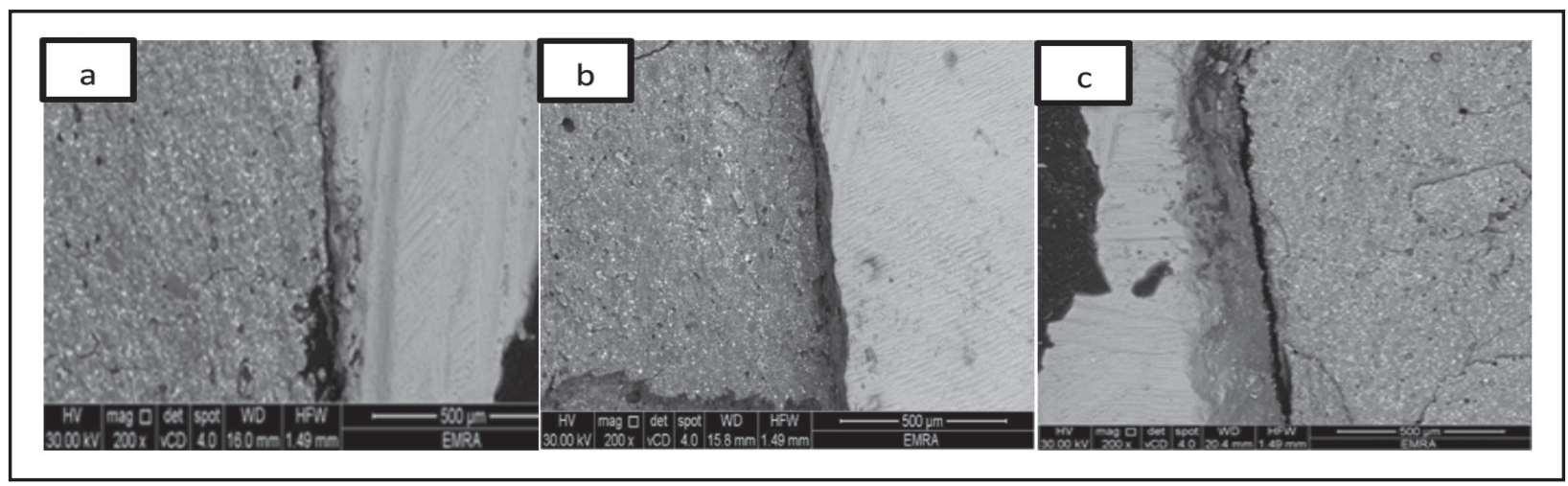

Fig. (3) a. SEM of Amalgomer CR at 24 hours storage, b. SEM of Amalgomer CR at 1month storage, c. SEM of Amalgomer CR at 3 month storage

\section{DISCUSSION}

Glass ionomer has several advantages including chemical bonding, fluoride release and biocompatibility. On the other side it is a weak material which make it is use in posterior region challenged. Several modifications have been done in to increase glass ionomers strength properties. Although failure of dental restoration occurs due to fatigue caused by repeated stresses with low value, but high stresses may cause fracture of the restorations. Therefor fracture toughness of high value is a very important parameter for selection of restorative material ionomers result in several generations which supposed to have high strength properties including fracture toughness.

Ceramic reinforced glass ionomer (Amalgomer $\mathrm{CR}$ ) which provides the dental clinicians the achieved benefits of glass ionomers in combination with amalgam strength properties. Glass hybrid (Equia Fort) is provided with second type of silicate particles which smaller and more reactive and acrylic acid with higher molecular weight which supposed to improve the material's mechanical properties. A highly viscous conventional GIC (Equia) with improved mechanical properties due to optimizing polyacid and particle size distribution.

In this study the fracture resistance of contemporary glass ionomers in class II cavities was tested. It was found that the fracture resistance of the studied restorative materials were noticeably different. The highest fracture resistance showed with Amalgomer CR which can be explained as follows; failure of glass ionomers occurs by crack propagations as it is brittle material. Amalgomer CR is a ceramic reinforced glass ionomer containing zirconia particles in the form of nano particles. Zirconia has unique property of a phase transformation from tetragonal to monoclinic under stress. A $4 \%$ volume change caused by this transformation produces a local compressive stress. This stress stops crack propagation through crack-opening tension offsets. This property makes zirconia particles excellent material for strengthening and increasing the material's fracture resistance. Also, ceramic filler is able to bond partially with the matrix as suggested by manufacturer (11). In addition to, presence of zirconia in form of nano particles help in increasing fracture toughness through crack pinning and deflection.

Besides, fracture resistance was found to be significantly increased after three months storage. This can be explained as follow; glass-ionomer cements belong to a class of materials known as acid-base cements. Concentrated solution in water is the media where Setting reactions occurs. Role of water; acts as a medium for reaction in which leaching and transportation of the cement forming cations occurs to react with polyacid to form a matrix hydrates siliceous hydrogel and formation of metal polyacrylate salts occurs. Water can be of two forms: first form, which displaced by dessication and called loosely bound water-second form, which is present 
in association with the hydration shell of the cation- polyacryate bond, especially that of aluminium and some silica gel water and cannot be displaced. The second form called tightly bound water and increased with aging increasing the strength, elastic modules and decreasing the plasticity ${ }^{(12)}$. This could account for the increased fracture resistance of glass ionomer with time.

The Increased adhesive failure with the time can be explained by the fact that the setting reaction of glass ionomer cements is associated with shrinkage. Tooth-glass ionomer adhesion interface do not resist shrinkage-stresses which results in formation of interfacial gap. Despite, water up take and swelling of glass ionomer after storage for 24 hours leads to expansion stresses (hygroscopic expansion) which compensates shrinkage-stresses. Compensation of hygroscopic expansion to shrinkage-stresses may not be sufficient to completely close the formed interfacial gap ${ }^{(13)}$. With time, water passes through the formed interfacial gaps causing hydrolysis of the restorative material with subsequent widening of the interfacial gap and more adhesive failure.

SEM pictures support the result of increased fracture resistance and adhesive failure with time. It was found that the fractured surface of the restorations showed reduced numbers and size of cracks and porosities with increased storage time especially after 3 months. Also the gap width at tooth restoration interface appears to be increased with time with predominance increase after three months.

\section{CONCLUSIONS}

Within the limitation of the present in vitro study the following conclusions could be derived:

1. Recent contemporary glass ionomers have improves fracture resistance.

2. Fracture resistance of cone temporary glass ionomers in class II cavities is affected by storage for 3 months.

3. Ceramic reinforced glass ionomer (Amalgomer $\mathrm{CR}$ ) appears promising regarding fracture resistance.

\section{REFERENCES}

1. Wilson D and Kent E. A new translucent cement for dentistry. The glass ionomer cement. Br Dent J 1972; 15: $132-3$.

2. Mount J.An Atlas of Glass Ionomer Cements: A Clinician's Guide. $3^{\text {rd }}$ ed. London: Martin Dunitz; 2002.

3. Lohbauer U. Dental Glass Ionomer Cements as Permanent Filling Materials? Properties, Limitations and Future Trends. Materials 2010; 3: 76-96.

4. Nagaraja P and Kishore G. Glass Ionomer Cement - The Different Generations, Trends. Biomater Artif Cell 2005; 18: $158-65$.

5. Mensudar R and Sukumaran G. To Evaluate the Effect of Surface Coating on Three Different Types Glass Ionomer Restorations. J Biomed Pharm 2015; 8: 445-9.

6. Gurgan S, Kutuk Z, Ergin E, Oztas S and Cakir F. Fouryear Randomized Clinical Trial to Evaluate the Clinical Performance of a Glass Ionomer Restorative System. Oper Dent 2015; 40: 134-43.

7. Schwendicke F, Kniess J, Paris S and Blunck U. Margin Integrity and Secondary Caries of Lined or Non-lined Composite and Glass Hybrid Restorations After Selective Excavation In Vitro. Oper Dent 2016; 4, 41-6.

8. Cugati S, Bhat $\mathrm{S}$ and Hegde S. Comparison of anticariogenic effect of amlgomer CR, Fugi VII and Heliomolar refill in the cavo surface margin. Int J Contemp Dent 2011; 2: 20-7.

9. Ayad N, Elnogoly S and Badie O. An in-vitro study of the physico-mechanical properties of a new esthetic restorative versus dental amalgam. Rev Clin Pesq Odontol $2008 ; 4: 137-44$.

10. Beresescu G and Brezeanu L. Effect of artificial saliva on the surface roughness of glass ionomer cements. Inter-eng 2011; 8: 134-6.

11. Ong J, Yap A, Hong J, Eweis A and Yahya A. Viscoelastic Properties of Contemporary Bulk-Fill Restoratives: A Dynamic-Mechanical Analysis. Oper Dent 2017; 42: 1-8.

12. Phillips R. Skinner's Science of Dental Materials. 9th Edn. Prism books private limited, New York 1991; 456-7)

13. Irie M, Maruoy, Nishgawa G, Suzuki K and Watts D. C. Class I Gap-formation in Highly-viscous Glass-ionomer Restorations: Delayed vs Immediate Polishing. Oper Dent J 2008; 33: 196-202. 